\title{
Aurkibidea
}

Editoriala 5

\section{Jatorrizko artikuluak}

Gaixotasun Traumatikoa eta trauma-sistemak

Iker Garcia Saez.

Afasia euskaraz aztertzeko tresna berria bidean: CAT testaren euskal egokitzapenaren gakoak eta estandarizaziorako urratsak

Marie Pourquie, Amaia Munarriz-Ibarrola

Sindrome mielodisplasikoa del $(5 q)$ isolatuarekin

Lide Ezenarro, Jose Ramon Furundarena, Anunciación Urquia

Kolon eta ondesteko minbizia bahetzeko programaren 10. urtea Euskadin

I. Portillo, I. Idigoras, I. Bilbao, E. Arana-Arri, L. Bujanda eta EUSKOLON taldea .. 35

Gehiegizko pisua 0-7 urteko adineko umeengan. Arrisku-faktoreak

Iratxe Escudero Otxandorena, Eva Pereda-Pereda, Izaro Babarro Velez, Juan J. Aurrekoetxea Agirre

Emakumezkoaren gernu-inkontinentzia

Maider Andres Arribalzaga 65

\section{Dosi txikitan}

Iktusa. Aro berri bat.

Amaia Muñoz Lopetegi, Maite Martinez Zabaleta

Anatorama: anatomia hiru dimentsiotan bistaratzeko aplikazioa

Jon Jatsu Azkue

\section{KAT}

Aspirinaren eraginkortasuna diabetikoetan

Mikel Moreno, Ina Idarreta

Arnas gutxiegitasun akutuaren kasuan sudurreko fluxu altuko kanularen erabilerak intubazio orotrakeal tasa gutxitu dezake

Cristina Agirre Rodríguez 
Aurkibidea

\section{Farmazialarien txokoa}

Sendagai umezurtzak, izendapenetik merkaturatze baimenerako ibilbidea

Maitane Umerez

INFAC, botika berrien eta i-botika fitxen azken hilabeteak

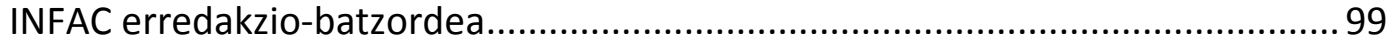

